\title{
The Finnish NATIONAL GALLERY'S INTERNET HOME PAGE IS INTO ITS THIRD YEAR
}

\author{
Eija Liukkonen and Mika Väyrynen
}

The Finnish National Gallery's Internet home page project was started by the National Gallery's museum pedagogical unit in early 1995. The completed home page launched September 26, 1995 under the address, http://www.fng.fil. The project's ambitious point of departure was to present a broad, multifaceted display of the Museum's collections. The aim was not only to impart information on current exhibitions and activities to different target groups but to truly function as a pedagogical tool for distance learning. The objective was to elicit genuine interest as well as to entice users to visit the Museum. Even occasional surfers can find themselves becoming regular museum-goers by virtue of the web.

The intention was to create a light, rapid and user-friendly system which would ensure proper legibility and image retrieval regardless of the quality of online connections or the software used. The trilingual home page format with Finnish, Swedish and English also represented a conscious choice. Making the information equally accessible to user groups outside Finland has become a priority: web-site browsers can be found anywhere from Uruguay to New Zealand.

In the very beginning, the most important thing was finding appropriate and enthusiastic partners. The Center for Scientific Computing (CSC) joined our project on condition that we would embark on something new and constructive which could be incorporated into the Ministry of Education's "Finnish Information Society" project. The original intent was, in fact, to create a pedagogically oriented system which would be both informative and inviting - something which divulged information beforehand and could inspire users to undertake actual visits. Teachers were seen as one natural target group.'

The idea was to make the Finnish National Gallery home page both distinguished and visually striking. The task was thus seen as challenging for graphic designers. The work load dictated the need for three graphic designers, all of whom were to be enlisted from the Department of Graphic Design at the University of Art and Design of Helsinki. Departmental interest in the design work was so 


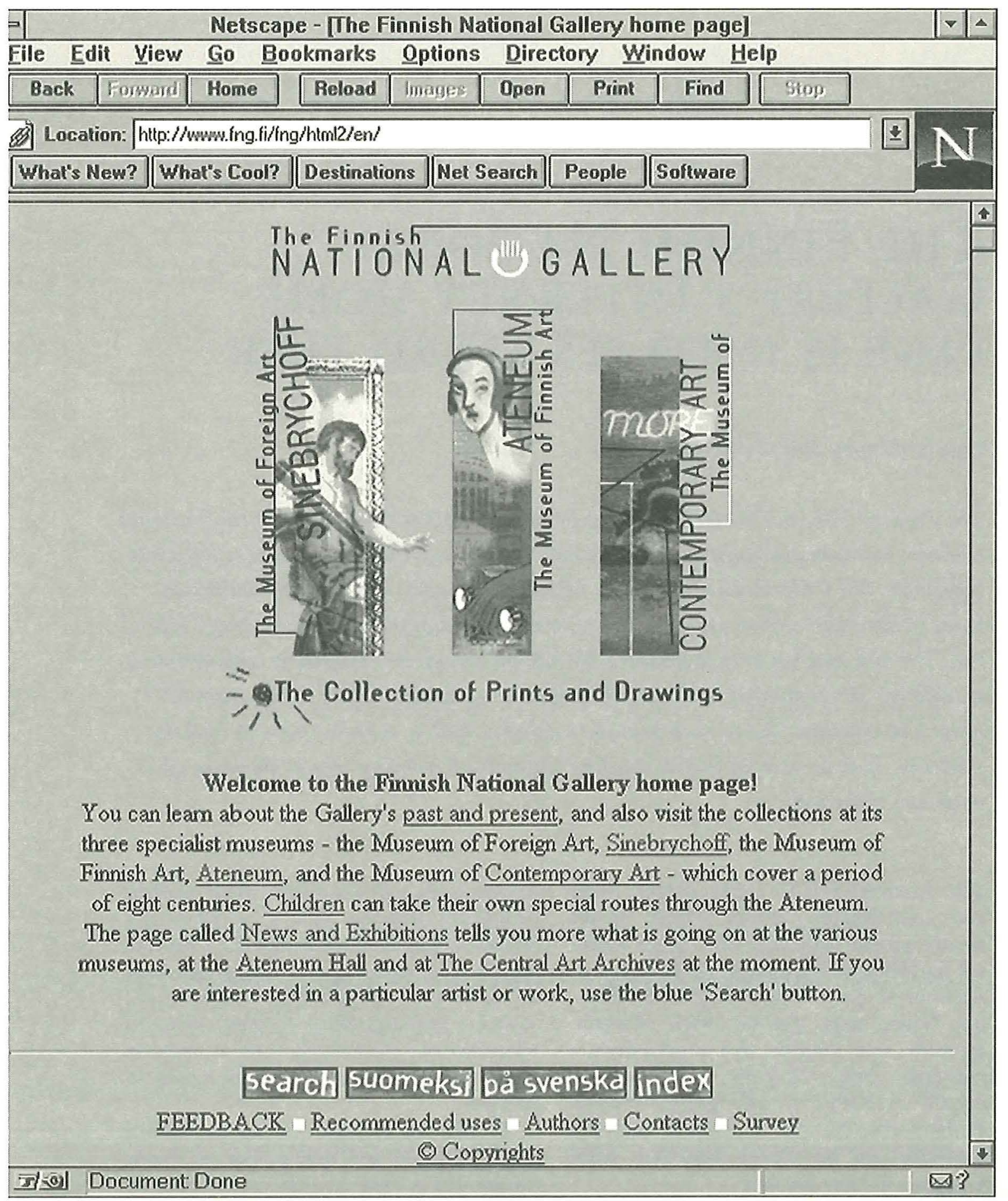

strong that the students' work was donated to the project. Susanna Pettersson and myself (Marjatta Levanto) from the museum pedagogical unit's of the Finnish National Gallery were responsible for the content. Funding had been sought from the Ministry of Education particularly for «the Finnish Information Society» project. This funding was to cover the programmer's salary and the subsequent 
copyright fees. Negotiations were started with the Visual Artists' Copyright Society Kuvasto concerning copyright payments to copyrightholders.

The Museum infact made history in the matter of reimbursements by being the first museum in the world to conclude an agreement with a Copyright Society. The actual workload came as a surprise, however. The community of artists outside the Artists' Copyright Society turned out to be quite large and each artist or other copyrightholder had to be contacted individually. A museum's existing electronic database is also a crucial factor influencing the system design process. In the case of the Finnish National Gallery, the Collection Management Database (VATI) served as the foundation for the presentation of the various collections. (Marjatta Levanto, Head of the Educational Department, the Finnish National Gallery).

The Finnish National Gallery's web project has neither been modelled on anything else nor does it have any precedents. Instead, the impetus has been to create something totally new. The few museum home pages that already existed were brief introductory pages. No one had previously integrated museum collections into the Web environment in quite the same manner. ${ }^{2}$ The practical problem was how to integrate the functions of three museums, four individual collections and seven different units.

The creation of a home page requires close cooperation between the different parties during the planning and execution stages. The project group worked practically day and night during the weeks preceding the launching of the home page scanning photographs of works, translating texts, finding copyrightholders, programming, and feeding information into the programs. The trilingual dimension of the home page increased the total workload even though the lion's share of the textual material had already been translated into Swedish and English when the project began. The integration of the Collection Management Database, VATI into the web project also constituted part of the workload. Information that had already been fed into VATI needed further checking, while artists and works needed to be reclassified and recoded specifically for the purposes of the web project. The conversion of the Finnish language database to suit the needs of the Swedish and English language home pages was not without its problems. Fortunately, the knowhow needed to solve future problems and to apportion workloads is readily available. For example, the staff of the Central Art Archives had experience in digital image processing.

The graphic artists responsible for designing the home page layout were also faced with a brand new challenge:

The sheer breadth of the material turned out to pose the project's biggest problem; how could collections and their histories, the presentation of works and artists, and museum guides hundreds of pages long be adapted to the web environment. The objective was to create an open, user friendly and visually distinctive user interface for a diverse range of interest groups from children to occasional net surfers, not to mention art researchers needing scientific accuracy. The graphic design of the Finnish National Gallery home page is not intended to divert attention from the artworks themselves. The visual language is not meant to have an expressive power that could overshadow the works in the collection. The intent is, rather, to serve the user and to support his/her mobility within a complex, informationally loaded system. At the same time, 
EIJA LiUKKONEN \& MiKa Väyrynen

32

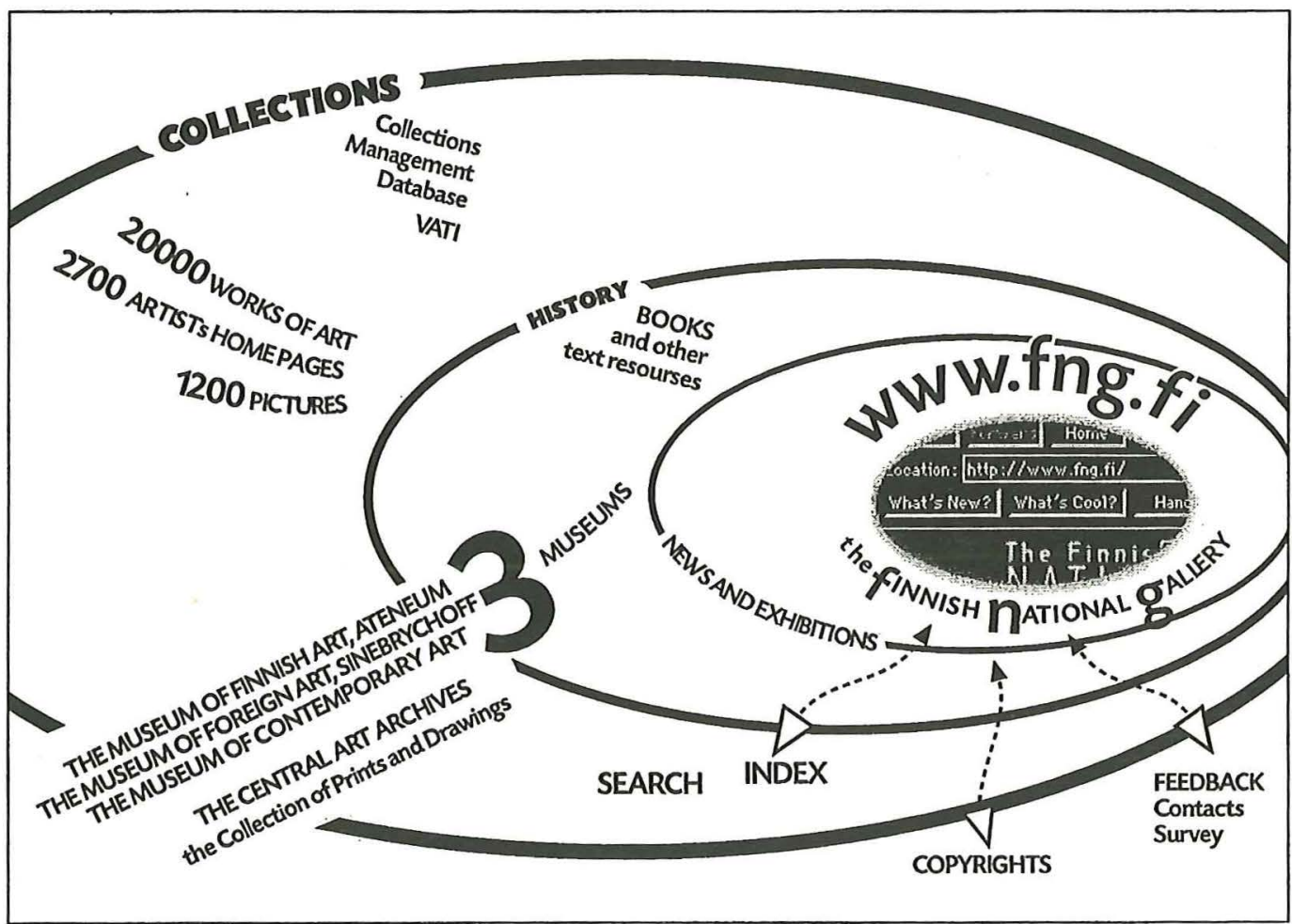

we would like to show that graphic design with a clear-cut informational mandate can still be fun, youthful and full of playful experimentation. (Sampsa Voutilainen, Graphic Designer) ${ }^{3}$

The graphic layout for the home page was chosen for inclusion in the Youth Forum '96 exhibition. ${ }^{4}$

\section{CONTENT}

The web directory's textual database contains all the written material from the various guides pertaining to Museum collections. ${ }^{5}$ These guides offer different approaches to getting to know the collec- tions. The approach to the Sinebrychoff collection in the Museum of Foreign Art, is historical whereas the Ateneum collection in the Museum of Finnish Art, is presented by way of different stylistic periods.

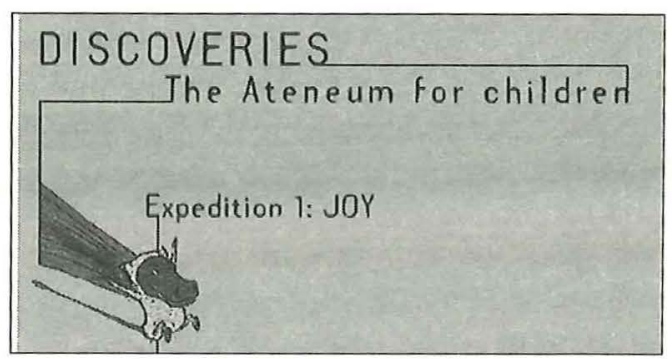

Scene from the Ateneum for Children 


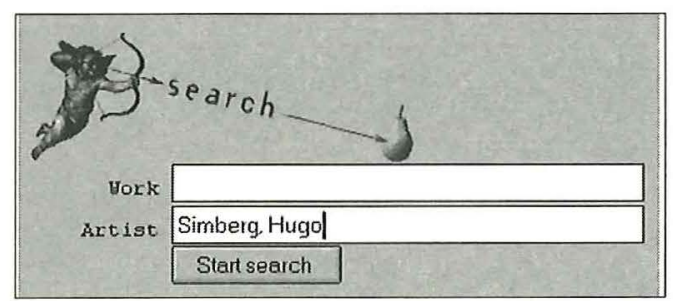

Search function

The aim of the guide to the Museum of Contemporary Art is, on the other hand, to provide different tools and perspectives for approaching contemporary art as well as for reflecting on the background ideas which give rise to particular formal solutions. There is a special Ateneum tour for children $^{6}$ and experiments have been carried out on the Finnish language web pages for the purpose of introducing a tour for deaf children conducted in sign language. ${ }^{7}$

In addition to navigation guides, different routes and search functions were also created for the web environment in order to facilitate browsing through each of the collections. The search function allows the user to become acquainted with the entire range of around 20000 artworks belonging to the Finnish National Gallery. This function makes it possible to access the home page of an artwork or an artist via either the name of the artist or the work.

Each gallery artist (some 2800 artists in all) also has his/her own home page. While the content of each home page varies according to the material available, the basic feature of every artist's home page is a listing of the artist's works which are represented in the Gallery's collections, including material specifications and dates. Additional materials of interest from the Central Art Archives such as letters, photographs and sketches form additions to the artists' home pages. The path to an artist's home page can be found both through guides and search tools.

Textual databases and search functions aside, one may also browse with the help of various menus: artists whose work is included in the collections of the Museum of Foreign Art, Sinebrychoff, can be located on the basis of nationality; works owned by the Museum of Finnish Art, Ateneum, can be located through recourse to the artist's stylistic direction, and artists associated with the Museum of Contemporary Art can be found on the basis of the decade in question.

The user can find out about current and future museum activities through News and Exhibitions pages. These contain basic information about current exhibitions, Ateneum Hall and workshop programmes, guided tours and other public events and services. They even contain

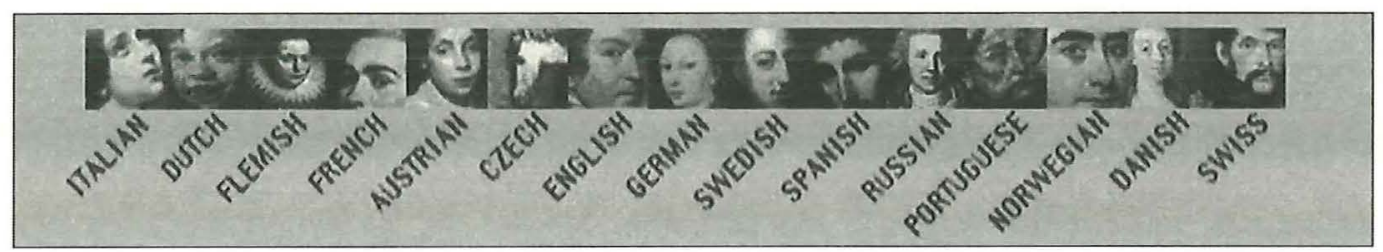

Menus: From the nationality menu you can go straight to the individual artists' home pages which tell you about their works in the National Gallery collection. Artists can be selected by nationality 
34 new library listings from the Central Art Archives. The content of News and Exhibitions pages is continuously updated. ${ }^{8}$ For example, the web entry concerning the 1996 Dialogues exhibition at the Museum of Contemporary Art included not only exhibition-related information but two artworks 9 designed to function within the web environment. A giftbook campaign for promoting Museum publications was also brought on line through the creation of an interactive order form.

\section{ATTENTION}

The project and the home pages were featured in numerous Finnish magazines as well as on radio and TV programmes immediately following the press conference. ${ }^{10}$ Needless to say, the launching of a home page was a much higher profile event two years ago than it is nowadays. An active marketing campaign was, of course, also needed to ensure that the information did not fall on deaf ears. The Finnish National Gallery's Concordia $1 / 96$ bulletin gave a lot of coverage to the web pages. There were also numerous postcard campaigns within the context of direct marketing. The active linking of the pages to the museum field's web pages was also a priority. The pages have been presented in different venues in Finland and abroad during the post-launching phase in an effort to reach different groups of users. ${ }^{11}$

Many cultural workers from around the world have responded favourably to both the content and the broad scope of the web pages. The project's breath was noted both in Finland and abroad. The subject was addressed in numerous publications. ${ }^{12}$
User comments and inquiries were received through the home pages every week. ${ }^{13}$ The comments about the web pages have mainly been positive.

Some of the inquiries were concerned with research projects or academic assignments; interest was expressed in either the entire web project or in individual matters such as copyright. More specific inquiries are passed on to those members of staff most capable of answering the query. The home pages were supplemented with contact information (including e-mail addresses) for the entire staff of the National Gallery organization. It is vitally important to respond to the feedback in one way or another. Here is some of the feedback:

- I was amazed when I first came across your page as I was doing some research on Art institutions on the net that might be linked to our (The European Union Working Group for Culture) page (www.ust.hk/-eucult/). I have printed some of your pages and forwarded them to my Finnish colleague so that we can have you listed at our "cool sites' cultural tour through Europe».

Since then, I have "visited" your Gallery many times myself. What can I tell you? The work you have done is outstanding! It is indeed rather rare to find such quality in introductory texts on the net, texts that you read with pleasure - the guided tour for children is just brilliant, the idea of grouping the paintings around a theme (joy, solitude) is so meaningful... I wish we had more of that and not only through the net.

Thank you so much for giving me the opportunity to learn about Finnish Art. I am now enjoying and looking at Hugo Simberg's works.

- I am writing a report for the European Comunity on web production by galleries and museums in 
Europe as part of the EC funded MAGNETS Project. I was impressed by your site and would like to use it as an example. Please could you help me by answering a few questions about the process that the Finnish National Gallery used to produce and maintain its web site.

Who was responsible for the initial Finnish National Gallery web site production and how were they chosen? Were they internal staff or was an external webmaster brought in to do it? If internal staff were/are used, was anyone hired to train them in web production and graphics? Who is responsible for the Gallery web site's maintainance, if it is not the same as the initial producer? What software and hardware (products, tools, suppliers) were used to produce the Finnish National Gallery site? What software and hardware are used to maintain the IMHS site? Do you have a in house web server, or do you rent web space from an internet provider? If you have an web server in house, what computer platform and web server software do you use, and what kind of connection do you have to the internet? If you rent web server space from an internet provider, who are they, what kind of deal do you have with them? Are you happy with the Finnish National Gallery web site as it is? Why or why not? What future plans do you have for the Finnish National Gallery web site, if any?

What advice would you offer to other European museums or galleries who want to produce a web site? Please feel free to write about anything else about your web site production that you feel is important.

Thanks in advance for answering my questions and including any additional comments, your help is greatly appreciated.

\section{USERS ARE THE FOCUS OF RESEARCH}

Potential web page users clearly constitute a user group who differ from the normal museum-going public. It is moreover evident that many web page users will not become actual museum-goers given geographical distances and other factors. While some web browsers are no doubt also museum-goers and representatives of affiliated groups, the new web constituency with its particular target groups needs to be seen as a challenge and a possibility. It also represents a compelling research focus.

The staff of the web project has been carefully monitoring the use of the home pages on a monthly and yearly basis since the beginning. ${ }^{14}$ Reports indicate a steady growth in use. Growth tripled from January 1996 to December 1996. ${ }^{15} 1997$ figures point to a slightly more moderate growth in use. Comparisons of the use of different language versions, and the location of users' countries of origin provide interesting information and feedback in addition to that obtained from monitoring numbers of users. In Autumn 1995, international communications accounted for some $20 \%$ of all feedback, while in August 1996 they accounted for almost $60 \%$ of all feedback. According to 1997 figures, approximately every second user resides outside Finland.

The home pages are used more on weekdays, with use peaking on Fridays and Tuesdays. The different web page sections are consulted with approximately the same frequency even though the Museum of Finnish Art, Ateneum collections and navigation guides elicit the greatest level of interest. In the case of the Finnish National Gallery's home pages, interest is predominantly directed towards Finnish art. The surfing is mainly done in English and Finnish, while only a small minority 
36 of browsers use the Swedish version.

When investigating home page use, attention should naturally be focused on the most popular pages and pictures without undervaluing the significance of those pages which elude the browser or which are simply ignored for lack of interest. The user monitoring process should be used as a tool for further development of the web pages. In evaluating feedback and use, it should be kept in mind that the nature of the medium precludes knowing precisely the reasons why a given user might react in a certain way. User dissatisfaction with the web pages might just as easily be due to maladjustments in his/her computer or program deficiencies as to the quality of the pages themselves.

Although information and research on web use and its users is being made available at an increasing pace, really knowing our own web constituency is vital to the development of our project. Who, what, to whom, why and how - such information must be at one's fingertips. Since the beginning of 1997, home-page users have also been monitored with the help of a web-based survey form. ${ }^{16}$ The Finnish Internet constituency continues, on average, to be young and male. According to the Internet user survey, the average age of users is 30,5 years, of whom $85 \%$ are men. ${ }^{17}$ According to the Museum's home page user survey, $45 \%$ of users are women and $55 \%$ of users are men. ${ }^{18}$ Average figures for actual Museum visits in the web are: $70 \%$ women and $30 \%$ men. ${ }^{19}$ The medium accesses new potential that is predominantly male and more international in character.

The following comments are based on the user survey: ${ }^{20}$

\section{CENTRAL EXPECTATIONS}

- I hope that they will retain their current breadth of scope. It's not necessary to have a great diversity of content since this can lead to the "phobia of plenty" so common in the net. The foundational artworks and some information about the artists just the way it is presented now is fine.

- Speaking as a professional in the field, I do like your sparse style.

- Is it really the case that whenever the municipality or the State is on board as a player, the end result is a bore, the pictorial treatment amateurish, etc.

- I was terribly disappointed when visiting your pages. Because they were so boring!

- Nowhere on this page could I find the city you were located in! How is a potential tourist supposed to make plans when he/she doesn't know where you are located? I would like to know your location.

- Didn't know where I was at first. No identifying name to all the pages.

- Who are you again?

- I vas waiting for factual information on the artists and pictures of their work.

- Diversity, ample content and high quality visuals (of which only the diversity was fully realised)

- I am searching for the Ateneum's opening hours as well as the cost of admission.

- I didn't have any expectations. This discovery came as a pleasant surprise.

\section{DEGREE TO WHICH \\ EXPECTATIONS WERE FULFILLED}

\section{PARTIAL REPLY:}

- Your pages are really extensive; therefore you should devote special attention to the internal hierarchy of the pages.

- Opening hours should be visible. 


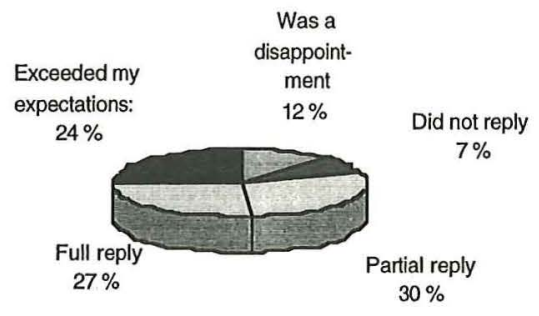

\section{DID NOT MEET MY EXPECTATIONS:}

- Insufficient text.

- Kiasma's pages look good; the layout of the other pages is old-fashioned.

- The multifaceted character of the sections is OK.

- The Search function works well, but information on artists is sparse.

\section{WHAT KINDS OF SERVICES WOULD YOU LIKE}

- That you keep them as nice as they are now.

- Whatever you do, do not turn it into a "candy store»; no animations, no additional background colours or icons; let art speak for itself.

- Links to artists. Artist of the month presentation.

- More picture illustrations and more information on artists.

- There is no way to contact you, except through this survey. You should have a list of your staff and their e-mail addresses available in the home page.

- There should be topical items that are fun.

- Links with art museums in the world. The SEARCH function needs further development: it was not clear to me where the artwork is physically to be found (in the Ateneum presumably??)

- Links with other art museums. Opening hours; prices. Perhaps they too could have been found somewhere, but now I didn't even look for them.

- Perhaps the showcasing of individual artists, although since it might be easier to read about them in books it would be good to have the reference information on the books in which the artists are featured.

- Ordering books, namely a listing of available books.

- I am wondering if I can get postcard, poster/print or book with a copy of River Landscape by Salomon van Ruysdael that is in your Sinebrychoff Museum. If so, please tell me the cost and I will arrange payment by credit card or whatever method you choose. Thanks for your help. I really want a copy of this painting.

\section{OTHER COMMENTS}

- Good and sufficiently broad in scope.

It's good that one can become acquainted with Finnish art in this way and have an esthetic experience. The net would be pretty dismal if this was not possible. Thank you for the good work.

- In being a first time browser of your web site, I was at ease going through various pages without being linked to pages I didn't want/need to go! Very Easy to Follow! Thank You!

- I'm very impressed by your efforts. The children's section is just wonderful- the best!

- The pages work well. Yet I would like to see it developed in a similar way to the Uffitzi Gallery presentation in the net.

- Great pages! Because of my personal interests, I would like to have had more information on conservation, yet it's fine even as it is.

- Some of the best home pages in Finland.

- I look for depth of information and possible paths to follow.

- Examples of works by the various artists would bring me back to this page.

- Examples of works- it's doubtful I'll ever get to Finland and thus visit the musems there so I'd like to see some of the works by Finnish artists.

- On some of the pages, the text spreads out all 
over the image display when the display opens to the entire width of the screen.

- Is it possible to print from the computer in colour a copy of Salomon van Ruysdael's Riverscape. I tried, but just got black copy???

- Have yet to spend a great amount of time, but am looking for ways to purchase prints, and have them shipped to the U.S.A.

\section{ORDINARY WORK}

The web project has been an essential part of the Educational Department work from the very beginning. At the same time, the project involves the entire Finnish National Gallery organization.

The search for copyrightholders, the making of contacts, the drafting and renewal of agreements, and reimbursements all continue to occupy the staff. The first visual copyright agreements were two-year agreements and a new round of copyright negotiations is coming up. The objective is, of course, to obtain longer periods of validity for the agreements as well as lower payments. The concluding of agreements with parties to an estate has been more difficult than originally anticipated. The problem was that although copyrightholders were easily located, the people concerned were distrustful and harboured a general lack of knowledge about the Internet context. A segment of the artists' community or of the copyrightholders were afraid of reproductions and of image manipulation. Some of the artists took a firm negative stand concerning the use of images in the context of the Internet. The execution of payments is also almost impossible because of tax regulations concerning parties to an estate, for example. Foreign artists are an additional problem (especially in the case of the Museum of Contemporary Art) because the copyright organizations in a number of countries have approached the practice of granting copyrights with caution (copyrights are not granted everywhere). Their arguments against copyrighting revolve around the dangers posed by illegal use. Our experience has emphasised the importance of clarifying the status of non-commercial image use in general. Both the content and the number of images in the home pages are a reflection of this situation. The pre-established budget for reimbursements imposes constraints on image quantity. The situation is naturally more clear-cut in the case of works belonging to collections than in the case of contemporary exhibition works. An exhibition may include both collection and non-collection works from different artists and copyrightholders whether Finnish or foreign. The exhibition web page is currently subject to conditions of agreement given the lack of consensus in copyright practice. The problems have yet to be straightened out.

Programme integration needs to be continuously monitored given the heavy reliance on the VATI system and its operational capability. Cooperation between the different Museum units is also essential for this reason. The acquisition of a new work for the collection also means that the home pages need to be updated. Although the number of artwork visuals (1200) cannot be significantly augmented under the current copyright situation, works by artists not bound by copyright are continuously scanned by Museum staff.

The News and Exhibitions pages are created practically from scratch in the 
three languages twice a year. Smaller home page updates are made on a weekly basis generally due to changes in programming. New image material is needed for both the current events and exhibitions pages and for the presentation of other events.

\section{RE-EVALUATION}

Two years in the life of home pages is a long time. The mere existence of the pages is not enough: renewal is part of the very nature of the medium. Re-organization and critical evaluation of content and materials is both necessary and natural even for the very medium itself. ${ }^{22}$ The received feedback and user survey only serve to confirm the importance of effecting thoroughgoing changes. The development of the medium has made the web pages look somewhat antiquated. Even though we're not about to experiment with the latest programmes and 3-D models, we are nevertheless busy preparing our second generation home pages. The same graphic artists as before are on board revamping the look of the home pages. The renewed web pages will be made public early in 1998.

The aim of the remodelling is to improve the user friendliness of the pages. In fact, the information content is being reorganized and re-categorized in order to make navigation easier. User feedback confirmed the difficulty in finding basic information, as well as opening hours, addresses and admission fees. The reason for this was that the page structure and layout emphasized the collections at the expense of "here and now» information. The web pages also made no allowance for the fact that a person browsing might "drop onto" to any page by using the search engines, thus the very possibility of

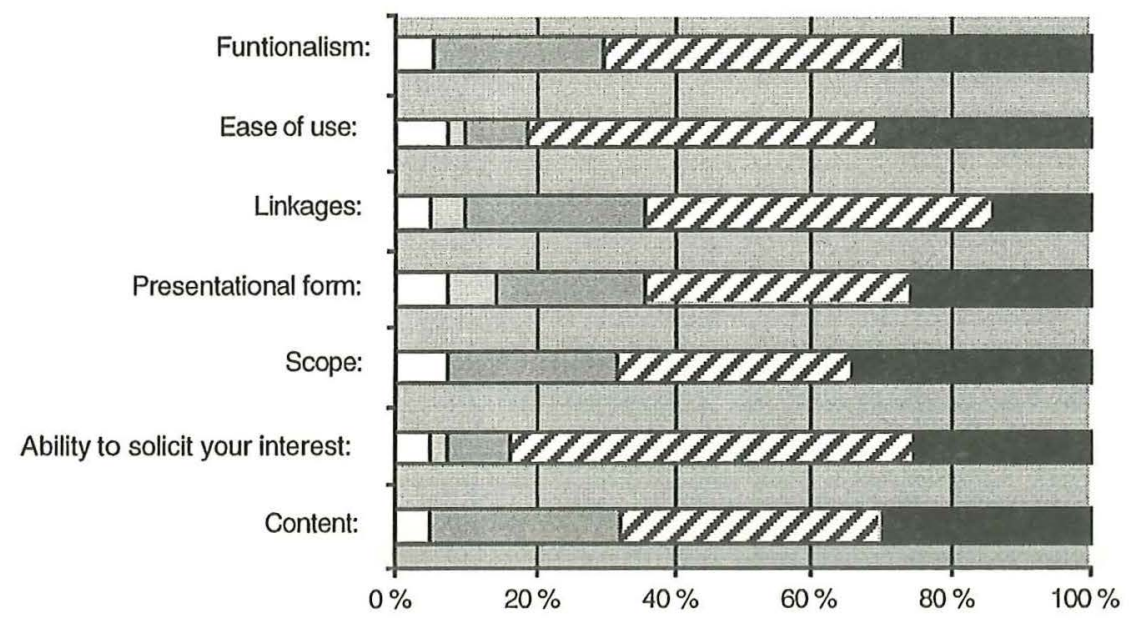

$\square$ Very poor $\square$ Poor $\square$ Average aGood $\square$ Very Good

Your personal evaluation of our home pages:21 
40 understanding the overall character of the pages and the museum context is simply not relevant.

Not only has the graphic look of the pages undergone a face-lift but the content itself is now broader than before. The Central Art Archive has brought its own resources to the project while contact information about the staff and units of the Finnish National Gallery will now be made available. User feedback expressed the desire for links to other pages in the museum field as well as for the convenience of being able to order various publications directly through the web pages. Launching the Museum of Contemporary Art's home pages in spring 1997 under the address http://www.kiasma.fng.fi/ also led to changes in the pages of the Finnish National Gallery. It is essential that both organizations combine their forces in the best possible manner. Language policy is a problem, however, as Kiasma's pages appear only in Finnish and English.

\section{BACK TO THE POINT OF DEPARTURE?}

The goals set at the start of the project have been realized. The pages were launched and the updating took place on time. The nature of the project has nevertheless changed over time. As outside interest in the home pages and their services grew, in-house staff also began to use them. News and Exhibitions pages have expanded and the workload has grown.

The web project requires a long-term maintenance and development plan as well as a formal commitment. Without this there is a danger that the project will spin out of control and end up in chaos.
The restrictions imposed at the beginnining of the project have actually been subject to re-evaluation. If the aim is to expand the content, this will tie up even more resources and will demand a more extensive commitment to the upkeep of the web pages. The ideal situation would be one where the producer of the original information (a unit or its staff member) would be solely responsible for updating and maintaining their pages. Hence the project would also grow vertically within the organization and could function naturally as an in-house system. More attention should also be paid to the life span of the pages. Given our current resources, it is not really very intelligent to compete against the clock to update one or two weeks worth of exhibition programming. Instead, it would be more productive to channel resources into information packages that are more timeless and that have a longer web life.

\section{WILL THE EVERYDAY MUSEUM WORK CHANGE?}

Practice has shown how important it is that the Museum staff watch over the home pages. To give the job of updating and maintaining the home pages to outside organizations has been found to be a poor and costly solution not only in Finland but elsewhere as well. ${ }^{23}$ Server maintenance and home-page updating require special skills making in-house competence in data communications, programming and related areas indispensable for the existence of the web pages. New job functions have come to stay in the museum world.

The Internet has brought speed and 
convenience to everyday tasks - it has become both a communications tool and an operational environment. For example, the news concerning the public announcement in spring 1997 about a notable artwork discovery (even by international standards) was immediately communicated to the world on-line. ${ }^{24}$ Communication has increased and has become more immediate. It is easy to direct people to the home pages and have them check their information no matter where in the world they might be located. Museum workers are also easier to reach- e-mail makes direct inquiries possible. A certain readiness to return communications and to sift out superfluous messages is nevertheless required of the staff.

The setting up of the World Wide Web has imposed on official bodies a challenging forum of communication and public service into which museums are also obliged to integrate themselves. After an initial period of enthusiasm, the original web page presentations have gradually been eclipsed by the more in-depth presentations and customized services increasingly offered by different museums. Museums are going virtual. We can, perhaps with good reason, say that the web is here to stay and that it will keep on growing for it has already achieved a firm place in Finnish society. The virtual museum has become one of the functional modalities of the contemporary museum. Information planning functions for the web have, in fact, been established in different museums. ${ }^{25}$ In-house know-how is necessary since this type of planning requires proper comprehension and mastery of the essential content. The internal intranet network will also serve to develop and speed up the Museum's in-house information transmission.

\section{FINALLY}

Three years in the web is a long time. Competition is hard in the network and changes need to be taken as challenges. The older home pages already have some historical value and the ones with the most multifaceted content will win out in the end. Cooperation between museums which are getting into the web is essential. This cooperation should extend from information management and system planning all the way to copyright practices.

\section{Special thanks:}

Marjatta Levanto, Head of the Educational

Department Tuula Hämäläinen, Attorney Juha

Inkari, Data Administration Planner

Translation: Kaj Oka

\section{NOTES}

1. Research in progress on the subject: University of Art and Design of Helsinki. Anne-Maija Issakainen. A visual art museum's prospects for the teaching of visual art examined. Information networks as channels for art.

2. The breadth is indicated by the approximately 4000 pages per language and the 1200 visuals of artworks.

3. Other graphic designers who worked on the project are Mari Pietarinen and Antti Raudaskoski.

4. Design Forum, January 23-February 25, 1996.

5. Susanna Pettersson. The Finnish National Gallery, 1992.

Marjatta Levanto. Ateneum Guide, 1987.

Marjatta Levanto. Discoveries, Ateneum for Children. 
Heikki Malme. The Collection of Prints and Drawings.

Aune Jääskinen. Icons.

Marja Supinen. Swedish portraits, miniatures, the Barbizon school.

Kai Kartio. The Art Collection Donated by Paul and Fanny Sinebrychoff. Paintings of the Sinebrychoff Collection.

Raimo Fagerström. Silver collection.

The Sinebrychoff Collection, Museum of

Foreign Art, Sinebrychoff, 1993.

Kaija Kaitavuori. Guide to the Museum of Contemporary Art, 1993.

6. Discoveries, the Ateneum for Children.

7. The demo-product is part of Antti Raikke's final project for the University of Art and Design of Helsinki entitled, "Dispersed Hypermedia for Information Retrieval by the Deaf".

8. Based on Concordia Bulletin.

9. Jan Erik Andersson's Puhdas/Ren/Clean which belongs to the Museum of Contemporary Art's collections, and Minna Heikinaho's Push Firma Beige.

10. Verkossa programme week 4 and week 43 .

Tietoverkko 3/96.

Information World Review, October 1996. Radio Mafia week 51.

11. For example: «Europe in Us» seminar, Museoliitto, 14.2.1996, Nordic Museum Fair, Gothenburg, 28-30.3.1996, Museum Technology course, University of Helsinki, 10.4.1996, Ammatti-instituutti 15.5.1996, Educa Fair, Helsinki, 28-30.11.1996.

12. ie. Programme week $4 / 96$ and week $43 / 96$, "Tietoverkko»3/96, Information World Review, October 1996.

13. Webmaster@fng.fi, Feedback and Visitor Survey pages.

14. Programmes: WWWusage v0.99 and analog 1.92beta1/Unix.

15. Www.fng.fi 1996 report. Finnish National Gallery.
16. Connected with the Finnish National Gallery's research project on museum-goers.

17. Internet User Survey 1997. Rissanen\&Järvinen Oy.

18. Web page user survey report 13.8.1997.

Finnish National Gallery.

19. Comparison 1996. Museum visitor survey report. Finnish National Gallery.

20. Web page user survey report 13.8.1997. Finnish National Gallery.

21. Ibid.

22. Museums and the Web: An International Conference 16-19.3.1997. Los Angeles, California.

23. Ibid.

24. Giovanni Domenico Tiepolo's (1727-1804) painting "The Greeks Enter Troy».

25. For example Information Planner, Media Art Curator, Information Systems Planner, Information Administration Planner (Finnish National Gallery).

Coordinator Eija Liukkonen works for the Finnish National Gallery's Educational Department and is responsible for the Web Project as well as survey research on the museum clientele.

Adr. Brunnsgatan 2, FIN-00100 Helsingfors

Fax $+358-17336248$

e-maileija.liukkonen@fng.fi

Project researcher Mika Väyrynen works for the Finnish National Gallery's Educational Department and is responsible for Ateneum Hall programming and the Web Project.

Adr. Brunnsgatan 2, FIN-00100 Helsingfors

Fax $+358-17336248$

e-mail mika.vayrynen@fng.fi 